This is the Accepted Manuscript version of an article published in Political Studies. For the Final Published PDF, please see:

Hjorthen, F.D., Humanitarian Intervention and Burden-Sharing Justice, Political Studies (Online first, 1 November 2019) pp. xx-xx. Copyright @ 2019 SAGE Journals. DOI: $10.1177 / 0032321719882607$.

\title{
Humanitarian Intervention and Burden-Sharing Justice
}

\author{
Abstract \\ This paper examines the case for distributive fairness among states in the \\ context of humanitarian intervention. I start by arguing that distributive fairness \\ among interveners is important for both intrinsic and instrumental reasons. I \\ then discuss the worry that due to the nature of humanitarian intervention, fair \\ burden sharing is difficult to achieve without compromising the operational \\ effectiveness of interventions. I examine three responses that whilst they reduce \\ the severity of this objection do not fully override it. Finally, in light of the \\ objection I explore options for practical changes and institutional reform that \\ could contribute to reconciling fair burden sharing with effective intervention. I \\ conclude that fairness and effectiveness can be reconciled in the longer term by \\ fully institutionalising humanitarian intervention and in the short term by \\ distinguishing between the duty to undertake intervention and the duty to pay \\ for it.
}

Keywords: duty to intervene; international justice; humanitarian intervention; responsibility to protect; distributive fairness. 
[Word count: $10250+$ abstract, keywords and acknowledgements]

\section{Introduction}

The debate on military humanitarian intervention has over the past decade-and-a-half been concerned with the notion of a duty to intervene (see e.g. Bagnoli, 2006; Caney, 2005; Fabre, 2012; Pattison, 2010; Tan, 2006; Tesón, 2005). ${ }^{1}$ Theorists disagree about the scope and grounding of this duty, but it is now widely, if not universally, accepted that there is a duty to intervene to protect people in other countries from egregious violations of their human rights. In international relations, this idea is captured by the Responsibility to Protect (R2P), which was endorsed by all UN member states in $2005 .^{2}$ Far less attention has been devoted to the more specific - and highly important - question of how the duty to intervene ought to be assigned to particular agents, or what we may call the duty specification question (Pattison, 2010: 2$).^{3}$

When answering the duty specification question there are at least two important desiderata. On the one hand, the duty should be assigned in a way that ensures that the intervention is effective. On the other hand, the duty should be fairly distributed between duty bearers. These two desiderata are usefully captured by Simon Caney's distinction between Harm Avoidance Justice and Burden-Sharing Justice. Harm Avoidance Justice 'takes as its point of departure the imperative to prevent [harm], and works back from this to deduce who should do what. Its focus is primarily on ensuring that the catastrophe is averted (or at least minimised within reason)'. Burden-Sharing Justice, meanwhile, focuses on 'how the burden

\footnotetext{
${ }^{1}$ I follow James Pattison (2010: 28) in defining humanitarian intervention as 'Forcible military action by an external agent in the relevant political community with the predominant purpose of preventing, reducing, or halting an ongoing or impending grievous suffering or loss of life.'

2 The focus of this paper is military humanitarian intervention, and not the Responsibility to Protect as such. Although R2P is relevant to several practical and theoretical aspects of humanitarian intervention, the concept as such is both wider and narrower. For an instructive account of R2P, see (Bellamy, 2006; 2011). For a more critical account, see (Hehir, 2010b).

${ }^{3}$ Tan (2006: 96) instead refers to it as the 'agency condition'.
} 
of combating the problem should be shared fairly among the duty-bearers' (Caney, 2014: 125-126). A harm may be prevented in several different ways, with each yielding a different set (or distribution) of burdens. Caney's idea is that if we are more focused on achieving the goal effectively, then we are taking a Harm Avoidance Justice perspective. If we are more focused on the distribution being fair, then we are taking a Burden-Sharing Justice perspective.

In the emerging literature on the duty specification question it is fair to say that the dominant approach has been one of Harm Avoidance Justice. Little attention has been devoted to distributive fairness among potential interveners. ${ }^{4}$ For example, James Pattison, in his major work on the duty specification question, devotes less than three pages to the question of fairness and burden sharing (Pattison, 2010: 196-199). Others, such as Caney (2005); Erskine (2014); Fabre (2012); Ralph and Souter (2015); Tan (1995; 2006; 2015) have also touched on the question of how the duties of intervention should be assigned, but they are similar to Pattison in that they pay little attention to distributive fairness among interveners. In this paper, I will argue that the relative neglect of Burden-Sharing Justice is mistaken, and I will start out by exploring the case for fair burden sharing for humanitarian intervention. ${ }^{5}$ However, a natural worry is that it would be difficult to achieve fair burden sharing without compromising the effective operation of interventions. This is because fair burden sharing seems to require that the duty be shared among a large number of agents, something that would lead to coordination problems and harm operational effectiveness. In the second part of the paper, I discuss this worry, and suggest three ways through which the effectiveness objection can be met. Although these responses reduce the scope and force of the objection, the effectiveness objection retains some bite. This leads to the question of how

\footnotetext{
${ }^{4}$ I will use the terms Burden-Sharing Justice, distributive fairness, and fair burden sharing interchangeably.

${ }^{5}$ Though I focus on humanitarian intervention, the arguments I present should in principle also be applicable to other structurally similar cases.
} 
the institutions and practices of humanitarian intervention may be reformed to facilitate both effective interventions and fair burden sharing.

In the final part of the paper I examine three practical approaches to how fair burden sharing and effective intervention can be reconciled more fully. Specifically, I argue that, in the longer term, we could fully reconcile effectiveness and distributive fairness by institutionalising humanitarian intervention. This is because institutionalisation would make it possible to divide the burden in a way that lends itself more easily to distribution among states. I also argue that, in the short term, we could reconcile effectiveness and distributive fairness by individuating the burdens of intervention more closely.

Thus, I defend two main claims: that Burden-Sharing Justice should play an important role for how the duty to intervene is assigned, and that this has important consequences for how we ought to specify the duties of humanitarian intervention in practice.

Two clarifications are in order before I proceed. First, it matters for the relevance of the duty specification question whether we think of the duty to intervene as a perfect or imperfect duty; that is, whether it is a duty of justice or a duty of beneficence. Generally speaking, imperfect duties of beneficence are duties that we cannot be compelled to perform and where no performer is specified (Bagnoli, 2006; Gomes, 2011: 1062; Nardin, 2006). To the extent that the duty to intervene is such a duty, the duty specification question will not arise. The duty to intervene would be assigned to everyone in general and not to anyone in particular. In this paper, I will assume that the duty to intervene is a duty of justice; i.e. one that agents can be compelled to perform. ${ }^{6}$ As Gomes (2011: 1064) puts it: 'Humanitarian intervention should $[\ldots]$ be recognised as a perfect duty that we could be required, even coerced, to perform.' The duty specification question arises when the duty to protect human rights, which all agents can be compelled to perform, is to be translated into a more specific

\footnotetext{
${ }^{6}$ For further discussion, see (Roff, 2011; Tan, 1995: 32-35).
} 
duty to undertake military humanitarian intervention and its task is to answer which desiderata should be applied so that the correct agents are picked out as the appropriate holders of this duty. To what extent distributive fairness should play a role in this process is the topic of this paper.

Second, throughout the article I will focus on states as the bearers of the duty to intervene. This follows a trend in the literature but should be seen as a simplifying assumption. A full account would consider other agents as well, and I submit that the duties to protect the rights of others (which ground the duty to intervene) ultimately attach to individuals. However, the assumption made here is reasonable seeing as states are individuals' main 'instrument for justice' when it comes to obligations in the international arena (Buchanan, 1999: 82-87). Hence, I acknowledge the important instrumental role of states whilst also retaining an individualist perspective regarding the ultimate site of rights and responsibilities.

\section{The importance of distributive fairness for humanitarian intervention and the effectiveness objection}

The duty to intervene entails a moral requirement that duty bearers carry the costs of intervention. Being morally required to bear these costs comes with demands for distributive fairness. This is so for both intrinsic and instrumental reasons. The claim that fairness is intrinsically important must ultimately be grounded in more fundamental principles (e.g. equal respect or concern for the legitimate entitlements of the citizens of intervening states). But given that there is a duty to intervene, and that the burden of acting on this duty must be borne by someone, there is a strong prima facie case for distributing it fairly. The instrumental argument for caring about distributive fairness for humanitarian intervention 
relates to the claim that distributing the burdens of intervention fairly can help alleviate the problem of undersupply of intervention. I return to this argument below.

It is important to note that I am here focusing on the burdens of intervention that are borne by the intervening parties. Humanitarian intervention of course also entails burdens for those in the target community or in the wider region. While such burdens are clearly important, they are not the topic of the present discussion. ${ }^{7}$

The burdens facing intervening states can be sorted into different categories. First, and perhaps all too obvious, humanitarian intervention is burdensome in the sense that some of the intervening soldiers will likely be killed, while others will sustain serious physical or psychological injuries. ${ }^{8}$ There is no doubt that this is a very serious burden, and it is also the case that such burdens cannot always be adequately compensated. However, someone might argue that it is ontologically suspect to say that this is a burden that befalls the state. In one sense, this seems true. It is the individual soldier (and his or her family and friends) that must bear this burden. ${ }^{9}$ But there are also costs associated with the loss of life and limb that more readily attach to the collective that comprises the state. First, when soldiers are wounded or killed in action the state will incur a cost in terms of reduced performance of its military forces. Soldiers that are wounded or killed can no longer contribute to the functioning of the military, and there will be costs associated with recruiting and training replacements. Second, the prospect of dead and injured soldiers implies indirect costs for the state in the form of health care and rehabilitation costs. This comes on top of any losses associated with a reduced tax base. Third, there may be downstream costs to the extent that the losses lead to difficulties in terms of future recruitment. This may harm the performance of the state's

\footnotetext{
${ }^{7}$ For discussion of how harm should be distributed between intervening soldiers, bystanders and the expected beneficiaries of intervention, see (McMahan, 2010; Øverland, 2011; Pattison, 2014).

${ }^{8}$ For an overview of the psychological effects on peacekeepers, see (Greenberg et al., 2008; Michel et al., 2003; Sareen et al., 2008; Shigemura and Nomura, 2002).

${ }^{9}$ This raises the question of whether anyone has a duty to risk their life in order to 'save strangers'. Space precludes further discussion of this important issue, but see (Fabre, 2007; Lango, 2001: 186).
} 
military forces and reduce its ability to function. Fourth, it may be that the loss of fellow soldiers affects the ability of the remaining troops to continue to function, perhaps because of severe stress and psychological harm. This may in turn affect the ability of the military to function as intended and may be seen as a cost that attaches to the state. Finally, it seems plausible that the loss of soldiers may lead to severe emotional distress for the citizens of the state in general (or at least large segments of it) and that this may lead to reduced welfare as well as reduced performance for various state functions. ${ }^{10}$ In light of this, the burden that soldiers may be killed or injured should be included in the analysis.

Second, and particularly important for democratic states, humanitarian intervention is burdensome in the sense that it might be politically costly. Even though engaging in humanitarian intervention can sometimes contribute to enhancing a state's international reputation for being a 'good international citizen', its own citizens might take a different view (Evans, 2008: 229; Pattison, 2010: 249). ${ }^{11}$ Engaging in humanitarian intervention might therefore prove costly at the next election. However, this burden seems to attach to the incumbent politicians rather than the state. It therefore seems strained to say that fairness requires that the political burdens be shared fairly among states. Moreover, such electoral costs are only relevant for democratic states and does not apply for interveners with undemocratic forms of rule. ${ }^{12}$ There is also the risk that humanitarian interveners will face sanction or attack from terrorists and/or other groups who are on friendly terms with the rights-violating regime or group that the intervention is meant to confront (Hjorthen and

\footnotetext{
${ }^{10}$ I acknowledge that this discussion does not fully capture all the forms of harm that are associated with the loss of life and limb for the individuals involved. However, for the purposes of the present discussion it is useful to break down the costs in this way.

${ }^{11}$ An illustrative example of the role of public opinion in this context is the reaction that followed the killing of 18 US soldiers in Mogadishu in 1993. For discussion, see (Wheeler, 2000: ch. 6 \& 7)

${ }^{12}$ For discussion of the importance of an intervener being representative of its citizens' opinions, see (Pattison, 2010: 131-134).
} 
Duus-Otterström, 2016). However, this may be very uncommon and the risk difficult to predict or quantify. For these reasons, political costs will be left out of the analysis.

Third, there is of course the economic and material burden. Humanitarian interventions often involve significant deployment of material resources and are typically very expensive. To take an example, the 2011 intervention in Libya is estimated to have cost the UK at least $£ 950$ million for air and sea operations alone (Guardian, 2011). In addition to the direct costs of the intervention there are also the indirect costs entailed by having military and other resources in a suitable state of alert. As Loren Thompson puts it in Forbes Magazine: '[...] what looks like an inexpensive military operation in Libya is actually costing taxpayers about $\$ 2$ billion per day, because that's what the Pentagon and other security agencies of the federal government spend to maintain a posture that allows the military to go anywhere and do anything on short notice' (Thompson, 2011). Having armed forces on stand-by for deployment in humanitarian interventions is hugely expensive, and the so called 'Revolution in Military Affairs' seen over the last couple of decades, with increasingly expensive technology and military assets, has arguably contributed to this (Diesen, 2013). In sum, unless otherwise specified, for the purposes of this paper I will consider the relevant burdens to be those that result from the loss of life and limb as well as the economic and material burdens facing contributing states.

What fairness is can be spelled out in various ways, but here I will accept John Broome's influential account. Broome contends that fairness is concerned ' $[\ldots]$ only with how well each person's claim is satisfied compared with how well other people's are satisfied.' Fairness requires that '[...] claims should be satisfied in proportion to their strength' (Broome, 1990: 95).

Applied to the case of humanitarian intervention, Broome's conception of fairness must be complemented by an account specifying a) what it is that states have a claim to, and 
b) what it is that determines the strength of their claims. Since humanitarian intervention is typically something potential interveners have an interest in avoiding, it seems reasonable to say with respect to a) that the relevant claims are states' claims not to intervene (or, put differently, their claims not to carry the burdens of intervention). As for b), there are several alternative factors that could answer the question of what should determine the strength of the claims, such as ability to contribute, cost effectiveness, historical responsibility, or some combination of these. ${ }^{13}$ The objective here is not to evaluate the relative merits of different distributive principles, so for ease of exposition, I will use capacity or ability to intervene as a running example. To say that $\mathrm{A}$ has the ability to intervene is to say that $\mathrm{A}$ has the quantitative and qualitative human and material resources required to contribute to the objective of protecting people's rights through humanitarian intervention. ${ }^{14}$ Obviously, this is a matter of degree. Applied to the Broomian view, this means that the burden of intervention ought to be distributed among states in proportion to their ability to contribute to the intervention. So, if, for example, France is twice as able as Belgium, then France should take on twice the burden. Against this background, the first claim I want to make is that it is simply important in itself that the burden of humanitarian intervention be shared fairly. Because ability is motivated by the need to enforce the victims' rights effectively, we may say that this principle represents a hard case for the objection I will soon present. If the objection has force against a distributive account focused on ability, it seems likely that it would have even more force against an account where factors orthogonal to effectiveness, such as historical responsibility or communal bonds, determine the distribution of the duty to intervene.

\footnotetext{
${ }^{13}$ For discussion, see (Hjorthen, 2017a).

${ }^{14}$ A more complex definition of ability would include factors such as cost effectiveness, but for the present purposes it will suffice to consider the simple, resource-centred notion of ability.
} 
But surely everyone thinks that fairness is good, it is only that distributive fairness among potential interveners seems a secondary concern in the case of humanitarian intervention. It is important to examine, therefore, whether there is a conflict between sharing the burdens of intervention fairly and effective intervention.

The case for fair burden sharing seems to face an immediate and strong objection, namely that fair burden sharing is not achievable without compromising the effective operation of interventions. I will refer to this as the effectiveness objection. To bring this out we must consider the implications of the account of fairness mentioned above whereby the burden of intervention is to be distributed proportionate to a relevant property, such as ability to contribute. Given that all, or at least most, states have the ability to contribute to an intervention to some extent it seems we would end up with a very significant number of intervening states. ${ }^{15}$ This would be distributively fair, but it also seems problematic because the burden of undertaking humanitarian intervention cannot easily be distributed among a large number of states without compromising the operational effectiveness of interventions. One might therefore agree with the intrinsic importance of fairness and still claim that effective Harm Avoidance should be prioritised when answering the duty specification question. After all, what seems most important (and what motivates the search for an intervening agent in the first place) is that the rights of the victims are protected. Even if the burden of undertaking humanitarian intervention is not shared fairly among states, this might well constitute a lesser injustice than that which would befall the victims in such cases where the intervention does not take place or else is assigned to ineffective agents.

To see how involving large numbers of states would be detrimental to effectiveness we have to consider what it is that makes for a successful humanitarian intervention. The

\footnotetext{
15 This is consistent with saying that some states would be unreasonably burdened by the duty and should therefore be exempted.
} 
prospects for success are much stronger when the response is quick; there is a clear and appropriate objective; there is a strategy in place that is appropriate for achieving that objective; sufficient and relevant material resources are committed; and there is the required political will to see it through (Hultman et al., 2013; Krain, 2005; Regan, 1996; Seybolt, 2007: 270). But whenever a significant number of states work together in military operations, problems of coordination, interoperability (both in terms of troops and equipment), national caveats, and buck-passing tend to arise, thus undermining the prospects for success (see e.g. Böhmelt et al., 2010: cited in; Ruggeri et al., 2013: 404). ${ }^{16}$ It is fair to assume that these problems will be particularly pronounced for interventions involving large numbers of states. Indeed, examples such as the MONUSCO peacekeeping operation in the Democratic Republic of Congo - which as of October 2017 included 15,982 contingent troops, staff officers and experts from 48 states - indicate that effectiveness can be severely hampered by coordination problems between contributing states. ${ }^{17}$ Moreover, while some argue that increased diversity in UN peacekeeping operations can in fact improve effectiveness, it is questionable whether this result can be extrapolated to operations involving a considerably greater number of states (Bove and Ruggeri, 2016). It seems, therefore, that there is a conflict between fair burden sharing and effective intervention. ${ }^{18}$

If the effectiveness objection is sound and fair burden sharing conflicts with effective intervention, then it seems we are faced with a choice in which fair burden sharing stands to lose out. After all, the objective of humanitarian intervention is to protect the rights of victims

\footnotetext{
${ }^{16}$ NATO defines interoperability as 'The ability to act together coherently, effectively and efficiently to achieve Allied tactical, operational and strategic objectives' (NATO, 2014: 2-I-8). For first-hand accounts of the challenges of interoperability, see (Bir, 1997; Cammaert, 2008).

${ }^{17}$ One could question whether this is at all an example of an intervention involving many states. Closer inspection of the data from the UN Department of Peacekeeping Operations reveals that $88 \%(14,155)$ of the military personnel come from the top ten contributors (UN, 2017a; 2017b). Despite this, it is probably the closest we can get to a contemporary real-world example of an intervention including a large number of states.

${ }^{18}$ Arguably, the effectiveness objection is not restricted to fair burden sharing. The objection applies to all burden sharing schemes that distribute the burden of intervention among a large number of states.
} 
of mass atrocities. Hence, the message of the effectiveness objection is that we would be ill advised to emphasise fair burden sharing when answering the duty specification question for humanitarian intervention. ${ }^{19}$ But does the effectiveness objection seal the fate of the argument for fair burden sharing for humanitarian intervention? In what follows I will consider possible responses to this challenge.

\section{Responses to the effectiveness objection}

In light of the effectiveness objection the case for fair burden sharing for humanitarian intervention seems rather weak. Given the importance of protecting the rights of the victims, it seems we should prioritise effective harm avoidance. But there are several responses that can be made against the effectiveness objection.

First, it is worth pointing out that the effectiveness objection does not rule out that the intrinsic value of fairness may sometimes determine how the duty of intervention should be distributed. It might be that in some cases fairness and effectiveness will coincide perfectly, and in such cases, fairness could be a tiebreaker. However, this is unlikely to happen very often. Hence, if the argument for distributive fairness is only relevant as a tiebreaker, the case for fair burden sharing seems quite weak. One could easily agree with the intrinsic importance of fairness but still claim that concern for distributive fairness is overridden by the need for effective intervention.

A second response is to say that even if the burden of undertaking humanitarian intervention should not be distributed among a large number of states, we can still accommodate fair burden sharing, albeit in a restricted sense. This response relies on a modification of what distributive fairness requires by adding an effectiveness proviso. Once

\footnotetext{
${ }^{19}$ The severity of this problem is particularly pronounced if states' claims not to intervene are determined by factors orthogonal to effectiveness, such as historical responsibility or communal bonds.
} 
such a proviso is included, the burden that is to be distributed is defined in terms of what it takes to realise the goal (in this case protecting the rights of the victims effectively). Hence, were we to distribute the task of undertaking humanitarian intervention among a great many states we would no longer be distributing the burden of realising the goal, but rather the burden of an ineffective attempt at doing so. This restricted conception of fair burden sharing avoids the effectiveness objection by adjusting the requirement of proportionality so that the burden is only distributed among the number of states that is compatible with the effective performance of the intervention. By way of example, if effectiveness is undermined by having more than five states sharing the burden, it would not be a problem of fairness (on this restricted account) if, for example, the UK, France, Germany, Italy, and Spain are the only ones to share the burden of intervention, provided the burden of realising the goal (of protecting the victims) is shared among these states in proportion to their ability. Yet, it is hard to escape the intuition that it would be more fair if the burden of intervention could be distributed in a way that more fully accommodates the requirements of (unrestricted) distributive fairness. For this reason, we should look for other responses to the effectiveness objection.

A third response comes in the form of what I will call the undersupply argument, which supplies an instrumental reason for caring about fair burden sharing for humanitarian intervention. The message of this argument is that victims of mass atrocities would benefit from fair burden sharing among potential interveners. This relies on the premise that a comparatively ineffective intervention can be better than no intervention at all. Indeed, it is trivially true that we cannot have 'effective intervention' without 'intervention'. Even if distributing the duty to intervene fairly would harm operational effectiveness, it could be that fair burden sharing among interveners would be good for the victims of atrocities because it can help solve the problem of undersupply of intervention. Hence, if we care about protecting 
the victims' rights, we should also care about distributive fairness among potential interveners. The argument I suggest can be summarised in the following way:

P1: States are unwilling to intervene in cases where the costs of intervention exceed a level L.

P2: Fair burden sharing involves distributing the costs among more states.

P3: Distributing the costs among more states makes it such that the cost facing each contributing state goes down, reducing the likelihood that it will exceed the level L.

C: Fair burden sharing helps increase willingness to intervene.

This argument rests on the assumption that the first hurdle to effective humanitarian intervention is that there is no intervention at all. Despite the (sometimes reasonable) criticism that has been levelled against humanitarian interventions that did take place, a far more common (and serious) problem is, and has been, interventions that did not take place, appropriately captured by Simon Chesterman's term ‘inhumanitarian non-intervention’ (2003: 54). There are, as Pattison notes, '[ ...] too many occasions when humanitarian intervention should be undertaken, but is not' (2008: 127-128; see also Seybolt, 2016: 563564). My argument is that by distributing the burden of intervention more fairly, more interventions that should take place would take place. Some may view this as controversial, arguing that intervention tends to make matters worse, and that we should therefore try to limit their number. But note that I am not arguing for more intervention tout court, but for more interventions that live up to reasonable criteria for permissibility (such as the ad bellum criteria in the Just War tradition). ${ }^{20}$ There is little doubt that states do not always heed such criteria, and there have been examples both of failed interventions (e.g. the UNOSOM II

\footnotetext{
${ }^{20}$ On which, see (Fixdal and Smith, 1998; Frowe, 2014).
} 
intervention in Somalia) and misuse of humanitarian arguments for ulterior purposes (e.g. the US and UK argument for the second war in Iraq, or the Russian argument in 2008 that it was invading Georgia to protect Russian-speaking minorities from genocide) (Glanville, 2014: 152-153; Pattison, 2010: 174; Seybolt, 2007: 272). Despite this, I believe this objection can be met by clarifying the baseline for measuring success. As Pattison notes: '[...] inflated expectations may mean that an intervention is wrongly seen as unsuccessful because it has not tackled all the problems that a society faces, even though [...] the situation is much better than it would have been without intervention (or any other course of action)' (Pattison, 2010: 83). It is probably true of most interventions that some negative consequences have resulted. Yet, it is unreasonable to count as a failure an intervention that saved more lives than nonintervention, or other available alternatives (Pattison, 2010: 83; Seybolt, 2007). ${ }^{21}$ On this reading of what counts as a successful intervention the number of failed cases is significantly reduced, and this largely undermines the objection. Hence, while we should reject calls for interventions that would make matters worse, this is not a major threat to the undersupply argument.

Let us now go through the premises of the argument. By way of defending the first premise, there is considerable support in the literature for the idea that lack of political will has on several occasions negatively affected the occurrence of interventions, and moreover that the often high political, material and economic costs of humanitarian intervention have a negative effect on political will (Bellamy, 2011: 172, 199; Evans, 2008: 218 \& ch. 10; Hehir, 2010a: 101-102, 124; Power, 2003: 508; Welsh, 2004: 5; Wheeler, 2000: 241, 299-304). ${ }^{22}$ But, as history shows, there have been several cases where states have undertaken humanitarian intervention. This means that at least some states are willing to intervene

\footnotetext{
${ }^{21}$ This is consistent with saying that intervention is sometimes impermissible because the prospects for success are too low or because the intervention would not live up to the requirement of proportionality.

${ }^{22}$ For discussion of undersupply in the sense that demand for intervention is not met by supply, see The People on War Report (ICRC, 1999: 74-79).
} 
provided they find the costs of doing so acceptable, or, put differently, that the costs do not exceed a certain level L. ${ }^{23}$ This suggests that bringing down the costs would indeed contribute to lowering the resistance towards intervening. Assuming that this can be done to a sufficient extent, the problem of undersupply would be mitigated.

As for P2, I assume that most reasonable principles for fair burden sharing would distribute the burden among a greater number of states compared to the current practice where interventions are generally performed by a small number of states. For example, even though some states can of course be expected to be a lot more able than others, it seems very likely that many states will have at least some ability to contribute. While there is no doubt that the US is the world's number one military power par excellence, the fact that many states contribute to UN peacekeeping operations, and/or are integrated in the structure of NATO shows that many states have at least some level of ability to contribute. Using the example of a proportional application of ability to contribute we would then have to conclude that the burden should be distributed among a large number of states. ${ }^{24}$

Finally, with regard to P3, it seems highly plausible that sharing the burden of intervention among more states would reduce the exposure of individual states to costs that they find unacceptable. Assuming that sharing the burden fairly would achieve this to a sufficient extent, more cases would be such that the costs facing contributing states would not exceed the critical level. This should lower states' unwillingness to participate in humanitarian intervention. Moreover, a second, moralised, version of this premise can be made, stating that distributing the costs among more states makes it such that the cost facing

\footnotetext{
${ }^{23}$ Whether this is plausible depends on how the notion of costs is fleshed out. Moreover, the argument does not apply to states that have strong principled objections to humanitarian intervention, or to states that lack relevant capacity to intervene. Such states either will not, or cannot, intervene, regardless of the costs.

${ }^{24}$ Whether the same logic would apply to principles based on, e.g., historical responsibility depends on how historical responsibility is defined as well as on the details of any particular case. The logic suggested above is more plausible on a broad reading of historical responsibility such as that suggested by Pogge (1992; 2008). However, it seems implausible that the duty to intervene should be assigned based on historical responsibility alone. For discussion, see (Hjorthen, 2017a; Pattison, 2011: 217).
} 
each contributing state goes down, reducing the likelihood that they will exceed the level where contributing to the intervention would be supererogatory. ${ }^{25}$ To the extent that states care about their moral obligations (perhaps a doubtful assumption, at least if the claim is that states care more about moral obligations than self-interest), the moralised P3 says that there will be more cases where the costs facing each state are such that contributing to the intervention is morally required, and that this would improve willingness to contribute.

Yet, P3 might face the objection that, if the burden of intervention were to be shared among more states, some states that up until now have avoided taking any of the cost of intervention would be required to take at least some of the cost, and this might be higher than what these states are willing to accept. Such states seem to have a self-interested reason to oppose taking on this cost, and thereby also to reject fair burden sharing. How, then, would fair burden sharing help solve the problem of undersupply? In response, it should be noted that while some states would have to contribute more than before, those that currently contribute the most would have to contribute less. This might make humanitarian intervention seem more acceptable to the governments and citizens of such states (an important point given that the states in question are often powerful states with significant influence over decisions about whether to intervene). This point seems even more plausible once we take into account a key tenet from realist international relations theory, which argues that states are particularly concerned with the distribution of relative power, and by extension with relative costs (see e.g. Waltz, 1979). It should also be noted that, under a fair system of burden sharing, the costs that each state would have to carry would likely be relatively low. Even though interventions are often costly, the moderate size of many states' ability to contribute would entail that their designated share would be quite modest. This is important, again, because it makes it less likely that the costs facing each state will exceed the level that

\footnotetext{
${ }^{25}$ For an argument that all permissible wars are in fact morally mandatory, see (Oberman, 2015).
} 
can be required as a matter of duty, and because it makes it harder for states to defend noncontribution (see e.g. Caney, 2005: 253; Pattison, 2010: 198). ${ }^{26}$ If the above is true - as seems highly plausible - then the net effect of fair burden sharing on the willingness of states to intervene would be positive.

Finally, it could be objected that P3 highlights an ambiguity in the argument. It might be that it is not fair burden sharing but simply burden sharing that is doing the work in terms of increasing willingness to intervene. In that case the desired effect could be achieved by distributing the burden among more states irrespective of whether the distributive scheme is fair. For instance, even if the burden was distributed among states according to a morally arbitrary factor such as the number of letters in their names, the burden would be distributed among a larger number of states compared to the status quo. In response to this objection I argue that there should indeed be an advantage to relying on fair burden sharing rather than distributing the costs among more states according to some arbitrary factor. This is because fair burden sharing should also contribute to the perceived legitimacy of intervention, something that would increase the likelihood that intervention takes place. ${ }^{27}$ This argument builds on the premises that i) there is a connection between sound principles of burden sharing and what people in general take to be good principles for burden sharing, and ii) that what people in general think about this matters for the political feasibility of intervention taking place. A distributive scheme based on unsound or clearly irrelevant principles would therefore undermine the undersupply argument. ${ }^{28}$ It is unlikely that states would accept a distributive scheme based on attributes as obviously irrelevant as, for example, the number of

\footnotetext{
${ }^{26}$ This might be explained by what is known in international relations theory as the 'logic of appropriateness'. On which, see (Finnemore, 1996: 28-31).

27 This argument is inspired by Brommesson and Friberg-Fernros (2013: 147-150), who argue that one condition for the feasibility of a R2P-regime lies in the logic of arguing: '[...] in order to be feasible in the long run according to the logic of arguing, an expanded regime on the use of force needs to be normatively persuasive' (2013: 148).

${ }^{28}$ Presumably, this is compatible with several different principles. This is not a problem for my argument.
} 
letters in a state's name. In the end, though, while the undersupply argument strengthens the case for fair burden sharing for humanitarian intervention, it is not obvious that fair but less effective intervention is always better than no intervention, or better than unfairly distributed but operationally more effective intervention. ${ }^{29}$ In such cases this response to the effectiveness objection is not available.

In sum it seems that there is a case for fair burden sharing in cases where the effectiveness objection does not apply; where we adopt a restricted account of fairness; or where some intervention is better than no intervention. This limits the scope and force of the effectiveness objection, but still it seems we cannot avoid the conclusion that concern for the victims will often override distributive fairness among interveners when deciding who should intervene. This raises the question of whether there are any practical or institutional solutions available that would allow us to reconcile effectiveness and fair burden sharing in light of the effectiveness objection.

\section{Achieving Harm Avoidance Justice and Burden-Sharing Justice for Humanitarian Intervention}

So far, we have seen that there is a prima facie case for sharing the burdens of humanitarian intervention fairly. But we have also seen that the case for fair burden sharing is vulnerable to the effectiveness objection. Several responses are available that reduce the scope and force of this objection, but the objection continues to show that it is difficult to achieve fair burden sharing without compromising the effectiveness of intervention. In this section I will examine three practical approaches that might seem to allow a role for fair burden sharing without running into the effectiveness objection.

\footnotetext{
${ }^{29}$ Moreover, a certain amount of epistemic humility is in order as the undersupply argument remains to be empirically tested.
} 


\section{Full institutionalisation of humanitarian intervention}

The idea of creating an international institution for humanitarian intervention has a long history and has been discussed by several theorists and practitioners (Bagnoli, 2006; Boyle, 2006; Buchanan, 2006; Buchanan and Keohane, 2004; 2011; Caney, 2005: 152-154, 162, 264; Kaysen and Rathjens, 1997; Kinloch-Pichat, 2004; Pattison, 2008; 2010: 229-236; Tan, 2006; Williams, 2005). The focus of these, however, has mainly been on potential advantages in terms of effectiveness and legitimacy. Less attention has been devoted to how institutionalisation might facilitate fair burden sharing.

Obviously, whether institutionalisation would have the desired effect would depend on the particulars of the institutional scheme. Space does not permit a full discussion of what it might look like, but some central factors are captured by Pattison, who suggests that a large, cosmopolitan UN volunteer force ought to be created, controlled by cosmopolitan democratic institutions and with its financial and material resources disentangled from the interests of major states $(2008 ; 2010: 233-236) .{ }^{30}$ The institution ought to have its own forces and capabilities, be sufficient in size to undertake several interventions at the same time, as well as having a separate mechanism for making decisions about when and where to intervene, be guided by an appropriate theory of jus ad bellum and jus in bello, and, importantly, have some form of secretariat or administration responsible for collecting and administering funds from states through an appropriate scheme for fair burden sharing. ${ }^{31}$

From the point of view of distributive fairness, the central advantage of full institutionalisation is that it would allow the distribution of the burdens of intervention

\footnotetext{
${ }^{30}$ For further discussion of decision-making and accountability in this context, see (Buchanan and Keohane, 2004).

${ }^{31}$ On which, see (Hjorthen, 2017b).
} 
without running into the effectiveness objection. When it comes to the burden of undertaking the intervention one can imagine two schemes whereby the burden could be distributed fairly. One option would be to say that when states voluntarily establish an institution tasked with undertaking humanitarian interventions, that moreover relies on volunteer forces, the problem of distributive fairness is resolved. It seems plausible that an agent that has been created to take on the burden and where those involved do so voluntarily has no claim to reject the burden of intervention. Another option would be to set up the institution so that states contribute troops and equipment in proportion to their ability, but where the force is controlled and operated by the institution on a permanent basis. Hence, even though the troops and equipment would come from individual states, the fighting would be done by the $\mathrm{UN}$ force qua UN force, thus avoiding the coordination problems that come with having a large number of states directly involved in the fighting. ${ }^{32}$ On either scheme, states would be left to share the economic burden of financing the institution. This is crucial seeing as distributing the burden of paying for intervention does not entail the same operational coordination problems as distributing the burden of undertaking intervention. Moreover, by having a mechanism for collecting funding from states, the institutional approach would facilitate sharing the economic burdens fairly. Compared to the current, state-based approach we would avoid having to calculate how much of a discount states that contribute militarily should get when it comes to their economic contribution, and it would become easier to take into account the long-term costs of military capabilities (these would be held by the institution but paid for by states). Moreover, if humanitarian intervention is paid for by everyone, the potential problem of historical taint - whereby the effectiveness of interventions is compromised by having historically responsible states pay for the

\footnotetext{
${ }^{32}$ Whether the second scheme could successfully combine operational effectiveness with distributive fairness would depend on the frequency of troop rotation as well as how often states' contributions would have to be adjusted for distributive fairness.
} 
intervention precisely because they are historically responsible - can more easily be avoided (Hjorthen and Duus-Otterström, 2016).

In sum, although institutionalisation of this kind does not guarantee distributive fairness, I have argued that it would make it easier to distribute both the burden of undertaking the intervention and the economic burden of intervention among states, with the added benefit that it helps spread out political and other costs. This should facilitate fair burden sharing for humanitarian intervention. But it is important not to forget that institutionalisation should also provide a comparative improvement in terms of effective harm avoidance. First, we would not have to go through the cumbersome process of deciding who should intervene on a case-by-case basis (Tan, 2006: 105). The institution would be the designated intervener and would thus be what Bernard Williams refers to as 'institutionally salient' to mass atrocity cases (Williams, 2005: 151). Relatedly, there is reason to believe that institutionalisation would improve consistency. One of the major critiques facing humanitarian intervention is that it is often selectively applied (Ayoob, 2002: 85-87). Since institutionalisation would improve both capacity for intervention and rely on impartial decision-making procedures regarding when and where to intervene, there is reason to believe that selectively would be less of a problem (Bagnoli, 2006: 133-134). Finally, an institution (as described) should be able to use and employ resources more effectively and be able to reap the rewards of economies of scale. This is important, both in itself and because, if the costs go down, the share of cases where humanitarian intervention is needed and where the costs are such that they fall within what can be demanded as a matter of duty would presumably go up. This means that we would more often be able to avoid tragic cases - that is, cases where the costs are such that an agent cannot be reasonably required to undertake the intervention, even if it is morally desirable (Caney, 2005: 253; Pattison, 2010: 198). Other things being equal this means that more lives can be saved. 
In sum, an institution for humanitarian intervention should prove useful for accommodating the differential concerns of effective intervention and distributive fairness. However, there are many further questions to be asked in relation to the desirability and feasibility of such a substantial reform. Indeed, in the short to medium term it is hard to see how such a massive reform could be put in place. It is therefore important to examine alternatives that might be more accessible in the near future.

\section{Alternating interveners}

A more feasible option in the short term might be to adopt a diachronic approach whereby the burden of intervention is shared fairly over time by having states alternate in taking on the burdens of intervention. On this view it is not required that the burden of intervention is distributed fairly for each intervention. This would avoid the problem of having an excessive number of states involved in each intervention. However, while this proposal seems feasible, three arguments undermine it. First, it might be that it would take a very long time to achieve a diachronically fair outcome. It would take a long time, or would require an implausibly large number of interventions, to achieve anything resembling proportionality. This is particularly problematic if we take an individualist view whereby individuals are the ultimate units of moral concern. For example, while the citizens of state A would take the cost of undertaking an intervention at $\mathrm{t} 1$, state B's citizens might take the cost of the next intervention at $\mathrm{t} 2$, at which point the good citizens of $\mathrm{A}$, who took the cost at $\mathrm{t} 1$, are no longer alive. Second, a more pragmatic point can be made that the practice of having alternating interveners would undermine the undersupply argument. That other states might contribute in the future might not be enough to alleviate states' concerns about costs. For example, A might not trust that $\mathrm{B}$ will take on the cost at $\mathrm{t} 2$, and therefore worry that it will be left with the costs again. A might take this as a reason not to act at $\mathrm{t} 1$. This is not an unreasonable 
worry. For example, when in 2006 the EU was called upon to send its Battlegroups to monitor elections in DR Congo, Germany, which was on rotation for the EU Battlegroups at the time, refused to lead the operation, and France and Britain were required to step in (Matlary, 2009: 173). Third, it can be argued that the idea of having alternating interveners is not viable. For the idea of alternate interveners to work it would have to be the case that different interveners would be selected each time. But it is not clear that different interveners can be chosen on each occasion without harming the effectiveness of the intervention. Given that the distribution of capacity for intervention among states is rather static, there are strict limits as to how much alternation there can be without compromising the effectiveness of interventions. Against this one could argue that having a system of alternating interveners could be effective over time even though it is not effective on each occasion. But that would of course be of little comfort to the victims in the perhaps many cases where the intervention is carried out by ineffective states. For these reasons it would be comparatively better if an alternative scheme for assigning the burdens of intervention could be found.

\section{Institutionalisation light - individuation of burdens}

Given the political and practical difficulties involved in creating a global force to undertake humanitarian intervention, in the short to medium term the best option might be to set up a more limited institutional scheme focused only on the economic burden of intervention. Hence, in contrast to most accounts of institutionalisation of humanitarian intervention, which tend to cover both the burden of undertaking intervention and the burden of providing funding (e.g., Bagnoli, 2006; Tan, 2006), the idea here is to focus only on the burden of paying for interventions. The idea that we can accommodate concerns of fairness by having some states undertake the intervention while others contribute in other ways, such as by providing funding and material resources, has been mentioned by several theorists. As Pattison suggests, '[...] although other agents may not have the duty to undertake 
humanitarian intervention, they may nevertheless have other, associated duties, related to the responsibility to protect and the prevention of human suffering that are equally demanding. These might include funding the intervention and providing equipment, and these will further offset any unfairness' (Pattison, 2010: 197-198). Relatedly, Cécile Fabre (2012: 190-191) has suggested that although some agents ought not to perform the intervention (for reasons of effectiveness), they can be required to bear a larger share in terms of funding the war and providing equipment. In line with these ideas, an institutional scheme focusing only on the burden of paying for intervention would help facilitate distributive fairness among states in the context of humanitarian intervention, albeit in a limited sense.

While this institutional scheme would only partially solve the problem of distributive fairness, the key benefit of singling out the burden of paying is that it makes at least part of the burden of humanitarian intervention amenable to distribution among a large number of states without running into the effectiveness objection. Specifically, while this proposal would not facilitate distributive fairness for the burden of undertaking intervention, it would allow us to employ an unrestricted notion of fairness for the duty of bearing the economic and material costs of intervention. Moreover, this would likely help distribute the political costs of intervention more widely. While it is perhaps not a requirement of fairness that these costs be distributed, it would certainly be advantageous in terms of alleviating the problem of undersupply. In sum, distinguishing between the burdens of intervention through an institutional scheme focusing only on the burden of paying for intervention, would (partly) accommodate distributive fairness by invoking associated duties (the duty to pay) for noninterveners without running into the effectiveness objection. ${ }^{33}$

\footnotetext{
${ }^{33}$ Over time, such a scheme could also be expanded to take into account the distribution of other duties relating to protecting people's rights, such as mitigating climate change or protecting refugees.
} 
Finally, although this to would require a level of institutionalisation, it seems quite feasible that such a scheme could be adopted. After all, the UN already has a system for distributing the costs of peacekeeping operations among states (Bellamy et al., 2010). ${ }^{34}$ The existing institutional set up could be amended to include funding for humanitarian intervention more generally. Moreover, this limited institutional scheme is compatible with having individual states join together to distribute the burden of undertaking interventions based on the restricted notion of fairness discussed above whereby the performance of the intervention is only distributed among a number of states compatible with the effective performance of the intervention. For these reasons, incorporating a scheme whereby the burden of funding interventions can be fairly distributed among states would enable a significant improvement in terms of fair burden sharing in the context of humanitarian intervention even in the absence of full institutionalisation.

\section{Conclusion}

In this paper I have examined the case for fair burden sharing when answering the duty specification question for humanitarian intervention. I have made two main claims: (1) that distributive fairness is important for humanitarian intervention, and (2), that this should be reflected in the institutions and practices for intervention. Supporting the first claim is the argument that fairness is important in itself. I then defended the case for fair burden sharing against the objection that it would compromise the effective operation of interventions. The objection showed that the case for distributive fairness is often overridden by the importance of protecting the rights of the victims, but as the final part of the analysis showed there are practical approaches available that allows us to reconcile our concern for the victims with

\footnotetext{
${ }^{34}$ For discussion of the UN scheme in the context of distributive fairness, see (Hjorthen, 2017b).
} 
distributive fairness among interveners. In the long term, effectiveness and fairness may be reconciled by creating an institution for humanitarian intervention, but in the short term we would do well to distinguish between the duty to undertake intervention and the duty to pay for it.

\section{Acknowledgements}

Previous versions of this article were presented at the Nordic Network in Political Theory in Uppsala; the Graduate political theory seminar, DPIR, University of Oxford; the Norwegian political science conference in Oslo; the MPSA Annual Conference in Chicago; the Norwegian political science conference in Stavanger; and at the Research Seminar in Practical Philosophy and Political Theory, University of Gothenburg. I gratefully acknowledge the helpful and constructive comments I received from the participants at these events. Special thanks go to my discussants at these events, Jouni Reinikainen, Grethe Netland, Natalia Kovalyova, Oluf Langhelle and Marcus Agnafors who provided extensive and helpful comments. Special thanks also go to James Pattison, Simon Caney, Kim Angell, Robert Huseby, Cornelius Cappelen, Göran Duus-Otterström, Henrik Friberg-Fernros, and the three anonymous reviewers of Political Studies who have all provided invaluable comments along the way.

\section{References:}

Ayoob M. (2002) Humanitarian Intervention and State Sovereignty. The International Journal of Human Rights 6: 81 - 102. 
Bagnoli C. (2006) Humanitarian Intervention as a Perfect Duty: A Kantian Argument. In: Nardin T and Williams MS (eds) Humanitarian Intervention. NOMOS XLVII. New York, NY: New York University Press, 117-142.

Bellamy AJ. (2006) Whither the Responsibility to Protect? Humanitarian Intervention and the 2005 World Summit. Ethics \& International Affairs 20: 143-169.

Bellamy AJ. (2011) Global politics and the responsibilty to protect: from words to deeds, Abingdon: Routledge.

Bellamy AJ, Williams P and Griffin S. (2010) Understanding peacekeeping, Cambridge: Polity Press.

Bir C. (1997) Interoperability and intervention operations. The RUSI Journal 142: 22-26. Böhmelt T, Metternich N, Pilster U, et al. (2010) The Effectiveness of Peacekeeping Missions in Civil Wars: Disaggregating Interventions, 1948-2000 Credibly Solving Commitment Problems.: Typescript, University of Essex and ETH Zurich.

Bove V and Ruggeri A. (2016) Kinds of Blue: Diversity in UN Peacekeeping Missions and Civilian Protection. British Journal of Political Science 46: 681-700.

Boyle J. (2006) Traditional Just War Theory and Humanitarian Intervention. In: Nardin T and Williams MS (eds) Humanitarian Intervention NOMOS XLVII. New York, NY: New York University Press, 31-57.

Brommesson D and Friberg-Fernros H. (2013) The feasibility of an expanded regime on the use of force: the case of the responsibility to protect. Journal of International Relations and Development 16: 138-166.

Broome J. (1990) Fairness. Proceedings of the Aristotelian Society 91: 87-101.

Buchanan A. (1999) The Internal Legitimacy of Humanitarian Intervention. Journal of Political Philosophy 7: 71-87.

Buchanan A. (2006) Institutionalizing the just war. Philosophy \& Public Affairs 34: 2-38. 
Buchanan A and Keohane RO. (2004) The preventive use of force: a cosmopolitan institutional proposal. Ethics \& International Affairs 18: 1-22.

Buchanan A and Keohane RO. (2011) Precommitment Regimes for Intervention:

Supplementing the Security Council. Ethics \& International Affairs 25: 41-63.

Cammaert P. (2008) A Peacekeeping Commander's Perspective. The RUSI Journal 153: 6871.

Caney S. (2005) Justice beyond borders: a global political theory, Oxford: Oxford University Press.

Caney S. (2014) Two kinds of climate justice: avoiding harm and sharing burdens. Journal of Political Philosophy 22: 125-149.

Chesterman S. (2003) Hard Cases Make Bad Law: Law, Ethics and Politics in Humanitarian Intervention. In: Lang A (ed) Just Intervention. Washington, DC: Gerogetown University Press, 46-61.

Diesen S. (2013) Towards an Affordable European Defence and Security Policy? The Case for Extensive European Force Integration. In: Matlary JH and Petersson M (eds) NATO's European Allies. Military Capability and Political Will. Basingstoke: Palgrave MacMillan, 57-70.

Erskine T. (2014) Coalitions of the Willing and Responsibilities to Protect: Informal Assiciations, Enhanced Capacities, and Shared Moral Burdens. Ethics \& International Affairs 28: 115-145.

Evans GJ. (2008) The responsibility to protect: ending mass atrocity crimes once and for all, Washington, DC: Brookings Institution Press.

Fabre C. (2007) Mandatory Rescue Killings. Journal of Political Philosophy 15: 363-384.

Fabre C. (2012) Cosmopolitan War, Oxford: Oxford University Press. 
Finnemore M. (1996) National interests in international society, Ithaca, NY: Cornell University Press.

Fixdal M and Smith D. (1998) Humanitarian Intervention and Just War. Mershon International Studies review 42: 283-312.

Frowe H. (2014) Judging armed humanitarian intervention. In: Scheid DE (ed) The Ethics of Armed Humanitarian Intervention. Cambridge: Cambridge University Press, 95-112.

Glanville L. (2014) Armed humanitarian intervention and the problem of abuse after Libya. In: Scheid DE (ed) The Ethics of Armed Humanitarian Intervention. Cambridge: Cambridge University Press, 148-165.

Gomes B. (2011) The duty to oppose violence: humanitarian intervention as a question for political philosophy. Review of International Studies 37: 1045-1067.

Greenberg N, Iversen A, Hull L, et al. (2008) Getting a peace of the action: measures of post traumatic stress in UK military peacekeepers. Journal of the Royal Society of Medicine 101: 78-84.

Guardian T. (2011) UK operations in Libya: the full costs broken down. Available at: https://www.theguardian.com/news/datablog/2011/sep/26/uk-operations-libya-costs [accessed 20 September 2016].

Hehir A. (2010a) Humanitarian Intervention. An introduction, Basingstoke: Palgrave Macmillan.

Hehir A. (2010b) The Responsibility to Protect: "Sound and Fury Signifying Nothing"? International Relations 24: 218-239.

Hjorthen FD. (2017a) Who Should Intervene? Res Publica 23: 391-407.

Hjorthen FD. (2017b) Who should pay for humanitarian intervention? European Journal of Political Theory 0: (epub ahead of print) 1-20. 
Hjorthen FD and Duus-Otterström G. (2016) Humanitarian intervention and historical responsibility. Journal of Global Ethics 12: 187-203.

Hultman L, Kathman J and Shannon M. (2013) United Nations Peacekeeping and Civilian Protection in Civil War. American Journal of Political Science 57: 875-891. ICRC. (1999) The People on War Report. Available at: https://www.icrc.org/eng/assets/files/other/icrc_002_0758.pdf [accessed 4 February 2016].

Kaysen C and Rathjens GW. (1997) Send In the Troops: A UN Foreign Legion. The Washington Quarterly 20: 207-228.

Kinloch-Pichat S. (2004) A UN'legion': between utopia and reality, London: Routledge. Krain M. (2005) International Intervention and the Severity of Genocides and Politicides. International Studies Quarterly 49: 363-388.

Lango JW. (2001) Is Armed Humanitarian Intervention to Stop Mass Killing Morally Obligatory. Public Affairs Quarterly 15: 173-191.

Matlary JH. (2009) European Union security dynamics: in the new national interest, Basingstoke: Palgrave Macmillan.

McMahan J. (2010) The just distribution of harm between combatants and noncombatants. Philosophy \& Public Affairs 38: 342-379.

Michel P-O, Lundin T and Larsson G. (2003) Stress Reactions Among Swedish Peacekeeping Soldiers Serving in Bosnia: A Longitudinal Study. Journal of Traumatic Stress 16: 589-593.

Nardin T. (2006) Introduction. In: Nardin T and Williams MS (eds) Humanitarian Intervention. NOMOS XLVII. New York, NY: New York University Press, 1-28. NATO. (2014) AAP-6. NATO Glossary of Terms and Definitions, Brussels: NATO. 
Oberman K. (2015) The Myth of the Optional War: Why States Are Required to Wage the Wars They Are Permitted to Wage. Philosophy \& Public Affairs 43: 255-286.

Øverland G. (2011) High-Fliers: Who Should Bear the Risk of Humanitarian Intervention?

In: Tripodi P and Wolfendale J (eds) New Wars and New Soldiers: Ethical Challenges in the Modern Military. Farnham: Ashgate, 69-86.

Pattison J. (2008) Humanitarian Intervention and a Cosmopolitan UN Force. Journal of International Political Theory 4: 126-145.

Pattison J. (2010) Humanitarian intervention and the responsibility to protect: who should intervene?, Oxford: Oxford University Press.

Pattison J. (2011) The Rights and Duties of Humanitarian Intervention: Who Should Intervene? A Reply to Two Critics. Global Discourse: An Interdisciplinary Journal of Current Affairs and Applied Contemporary Thought 2: 213-217.

Pattison J. (2014) Bombing the beneficiaries: the distribution of the costs of the responsibility to protect and humanitarian intervention. In: Scheid DE (ed) The Ethics of Armed Humanitarian Intervention. Cambridge: Cambridge University Press, 113-130.

Pogge TW. (1992) An Institutional Approach to Humanitarian Intervention. Public Affairs Quarterly 6: 89-103.

Pogge TW. (2008) World Poverty and Human Rights. 2nd Edition, Cambridge: Polity Press.

Power S. (2003) "A problem from hell": America and the age of genocide, New York, NY: Harper Perennial.

Ralph J and Souter J. (2015) A special responsibility to protect: the UK, Australia and the rise of Islamic State. International Affairs 91: 709-723.

Regan PM. (1996) Conditions of Successful Third-Party Intervention in Intrastate Conflicts. The Journal of Conflict Resolution 40: 336-359. 
Roff HM. (2011) A Provisional Duty of Humanitarian Intervention. Global Responsibility to Protect 3: 152-171.

Ruggeri A, Gizelis T-I and Dorussen H. (2013) Managing Mistrust: An Analysis of Cooperation with UN Peacekeeping in Africa. Journal of Conflict Resolution 57: 387409.

Sareen J, Belik S-L, Afifi TO, et al. (2008) Canadian Military Personnel's Population Attributable Fractions of Mental Disorders and Mental Health Service Use Associated With Combat and Peacekeeping Operations. American Journal of Public Health 98: 2191-2198.

Seybolt T. (2016) The Use of Force. In: Bellamy AJ and Dunne T (eds) The Oxford Handbook of the Responsibility to Protect. Oxford: Oxford University Press, 562-581.

Seybolt TB. (2007) Humanitarian military intervention: the conditions for success and failure, Oxford: Oxford University Press.

Shigemura J and Nomura S. (2002) Mental health issues of peacekeeping workers. Psychiatry and Clinical Neurosciences 56: 483-491.

Tan K-C. (1995) Military Intervention as a Moral Duty. Public Affairs Quarterly 9: 29-46.

Tan K-C. (2006) The Duty to Protect. In: Nardin T and Williams MS (eds) Humanitarian Intervention. NOMOS XLVII. New York, NY: New York University Press, 84-116.

Tan K-C. (2015) Humanitarian Intervention as a Duty. Global Responsibility to Protect 7: $121-141$.

Tesón FR. (2005) Humanitarian intervention: an inquiry into law and morality, Ardsley, NY: Transnational Publishers.

Thompson L. (2011) The Real Cost Of U.S. In Libya? Two Billion Dollars Per Day. Available at: http://www.forbes.com/sites/beltway/2011/03/28/the-real-cost-of-u-s-inlibya-two-billion-dollars-per-day/\#2e1fc2a23f98 [accessed 2 April 2017]. 
UN. (2017a) MONUSCO Fact Sheet. Available at:

https://peacekeeping.un.org/en/mission/monusco [accessed 18 January 2018].

UN. (2017b) Summary of Contributions to Peackeeping by Mission, Country and Post, 30/11/2017. Available at:

http://peacekeeping.un.org/sites/default/files/mission_country_post.pdf [accessed 3 January 2018].

Waltz KN. (1979) Theory of international politics, New York, NY: McGraw-Hill.

Welsh J. (2004) Introduction. In: Welsh J (ed) Humanitarian intervention and international relations. Oxford: Oxford University Press, 1-10.

Wheeler NJ. (2000) Saving strangers: humanitarian intervention in international society, Oxford: Oxford University Press.

Williams B. (2005) Humanitarianism and the Right to Intervene. In: Hawthorn G (ed) In the Begining Was the Deed - Realism and Moralism in Political Argument. Princeton, NJ: Princeton University Press, 145-153. 